\title{
Catálogo de estelas discoideas de época medieval pertenecientes al yacimiento de "La Mezquita" (Cadalso de los Vidrios, Madrid)
}

\section{Catalog of discoidal stelae from medieval times belonging to the "La Mezquita" site (Cadalso de los Vidrios, Madrid)}

José Miguel Hernández Sousa ${ }^{1}$

Recibido: 09-03-2018

Aceptado: 24-09-2019

\section{Resumen}

Las intervenciones arqueológicas que se han llevado a cabo en los últimos años en el yacimiento de "La Mezquita" (Cadalso de los Vidrios, Madrid) han servido para recuperar un conjunto de materiales diversos que abarcan desde el siglo XI hasta la actualidad. Uno de esos materiales son las estelas discoideas que fueron usadas como marcadores de enterramientos para que familiares y amigos no olvidaran al finado. El uso de estos elementos comprende una cronología que abarca, principalmente, los siglos XI-XIV cuando, una vez cumplida su función primordial, serán empleadas en una secundaria, como elementos constructivos.

\section{Palabras clave:}

Estelas discoideas, Cadalso de los Vidrios, enterramientos, intervenciones arqueológicas.

\begin{abstract}
The archaeological interventions that have been carried out in the last years in the site of "La Mezquita" (Cadalso de los Vidrios, Madrid) have served to recover a set of diverse materials ranging from the XIth century to the present day. One of these materials are the discoid stelae that were used as markers of burial so that family and friends do not forget the deceased. The use of these elements includes a chronology that covers, mainly, the XI-XIV centuries when, after completing their primary function, they will be employed in a secondary school, as constructive elements.
\end{abstract}

\section{Key words:}

Discoid stelae, Cadalso de los Vidrios, burials, archaeological interventions.

\footnotetext{
1 Departamento de Prehistoria y Arqueología de la Universidad Autónoma de Madrid; josemiguel.hernandez@predoc.uam.es
} 


\section{INTRODUCCIÓN}

Es un sentimiento general en toda sociedad la idea de la muerte y, ligada a ella, el recuerdo de los seres fallecidos, algo que desde siempre ha estado muy presente en la mente humana. Ya desde la Prehistoria se muestra un destacado interés por señalar el lugar donde descansan los restos del finado y para ello, uno de los diferentes modelos utilizados fueron las estelas.

Desde finales del siglo XVIII cuando el padre Tomás de Burgui se refiere en sus escritos a la estela de Errotabidea, aportando su dibujo, las estelas funerarias despertarán el interés de los investigadores. La fundación de las Comisiones de Monumentos históricos y artísticos fundadas a lo largo de la década de los 40 del siglo XIX, marcará una preocupación por la protección del patrimonio cultural de cada provincia; a la comisión de la provincia navarra se debe una destacada preocupación por el tema que nos ocupa, las estelas, en principio preocupados por la romana y a partir de la segunda década del siglo XX de las discoideas (Quintanilla Martínez, 1995: 583-585). Poco después Eugeniusz Frankowski (1920) recopiló en una importante publicación un primer catálogo en que se reunían las conocidas hasta el momento, que posteriormente se han visto incrementadas en un numero exponencial. Será en las últimas décadas del siglo pasado cuando vean la luz un importate número de artículos que fueron dando a conocer la diversidad y amplitud de este monumento. Finalmente, será a través de la celebración de los Congresos Internacionales de Estelas Funerarias, celebrados entre 1993 y el año 2002, cuando se sistematice y reunan sus estudios, que durante estos años han seguido en aumento.

Las estelas funerarias son una clase de monumento cuyo uso se encuentra documentado por toda la península ya desde la Antigüedad. Sera durante la época romana cuando el empleo de la estela con forma discoidea se generalice (Nogales Basarrate, 1994). Tras un período de decaimiento, será a partir de la etapa altomedieval cuando de nuevo se retome este hábito, ya con los motivos tradicionales que conocemos, signos astrales, cruces, geométricos, vegetales, etc., hasta alcanzar un momento de máximo empleo entre los siglos XII a XIV momento en el que comienza a decaer su uso (Menchón Bes, 2004: 672).
Debemos decir que nunca se dejó de utilizar y que en la actualidad son un elemento que continúa de moda en algunas zonas peninsulares. Tenemos constancia documental de su uso a través de la iconografía, en concreto la miniatura de las Cantigas de Santa María donde se puede observar la presencia de estelas discoideas con ataúdes o sarcófagos en un camposanto medieval ${ }^{2}$.

Las estelas funerarias de tipo discoideo se vienen fechando en un contexto arqueológico desde la Antigüedad tardía hasta la baja Edad Media (Menchón Bes, 2004: 672). Aquellas que se han fechado en época altomedieval su cronología ha sido establecida por estar adscritas a edificios datados arqueológicamente en ese momento (Casa y Doménech, 1983a),

En cuanto al significado de su forma, son dos las tendencias bien diferenciadas han dividido desde hace décadas a los investigadores sobre su origen, aquellos que defienden un significado antropomorfo de la misma, llegando a insinuar una posible procedencia de la esquematización de bustos de difuntos (García Guinea, 2004: 24); o los que consideran que estas piezas eran en su origen manifestaciones de culto astral (González Calle, Mayoral Castillo, y Savirón Cuartango, 2009: 169).

Hay que destacar que su función es similar a la del epitafio sepulcral realizado sobre losa, informarnos sobre el lugar donde yace el difunto y a quien pertenece. Sin embargo, una parte muy elevada del conjunto de estelas conocido son anepigráficas, lo que sugiere un uso únicamente funcional, marcando el lugar del enterramiento. Parecen ser un elemento destacado en las sociedades rurales, que algunos han querido relacionar con los primitivos núcleos eremíticos (Martín López, 2017: 247), algo que no tiene una lógica justificación desde nuestro punto de vista.

Los cristianos desde muy pronto se sintieron atraídos por enterrarse en espacios sagrados, de este modo el espacio eclesial se convierte en el lugar preferente para su descanso eterno. Durante los siglos altomedievales los cementerios cristianos fueron creciendo en asociación a los edificios cultuales. Este interés por los enterramientos en el interior de espacios sagrados motivó que en el siglo $\mathrm{VI}^{3}$, las autoridades eclesiásticas prohibieran los enterramientos en su interior (Vives, 1963: 75). A pesar de que esta prohibición

\footnotetext{
2 Más concretamente en una miniatura del Códice Rico de las Cantigas de Santa María, Cantiga CLXIV de Alfonso X en el Monasterio de El Escorial, donde se observan las estelas discoideas situadas en la cabecera de la sepultura.

3 Así aparece reflejado en el canon XVIII del Concilio de Braga del año 561: "De corporíbus defunctorum. (De corporíbus homínum íntra baselícas sanctorum nullatt;nus sepelliendis.) ítem placuit, ut corpora defunctorum nullo modo íntra basílícam sanctorum sepeliantur, sed sí necesse est de forís circe murum baselicae usque adeo non abfiorret. Nam si fírmissímum fioc previlegium usque nunc retinent cívitates, ut nullo modo intra ambítus murorum cuíuslíbet defuncti corpus tiumetur, quanto magís fioc venerabílíum martyrum debet reverentía obtínera”.
} 

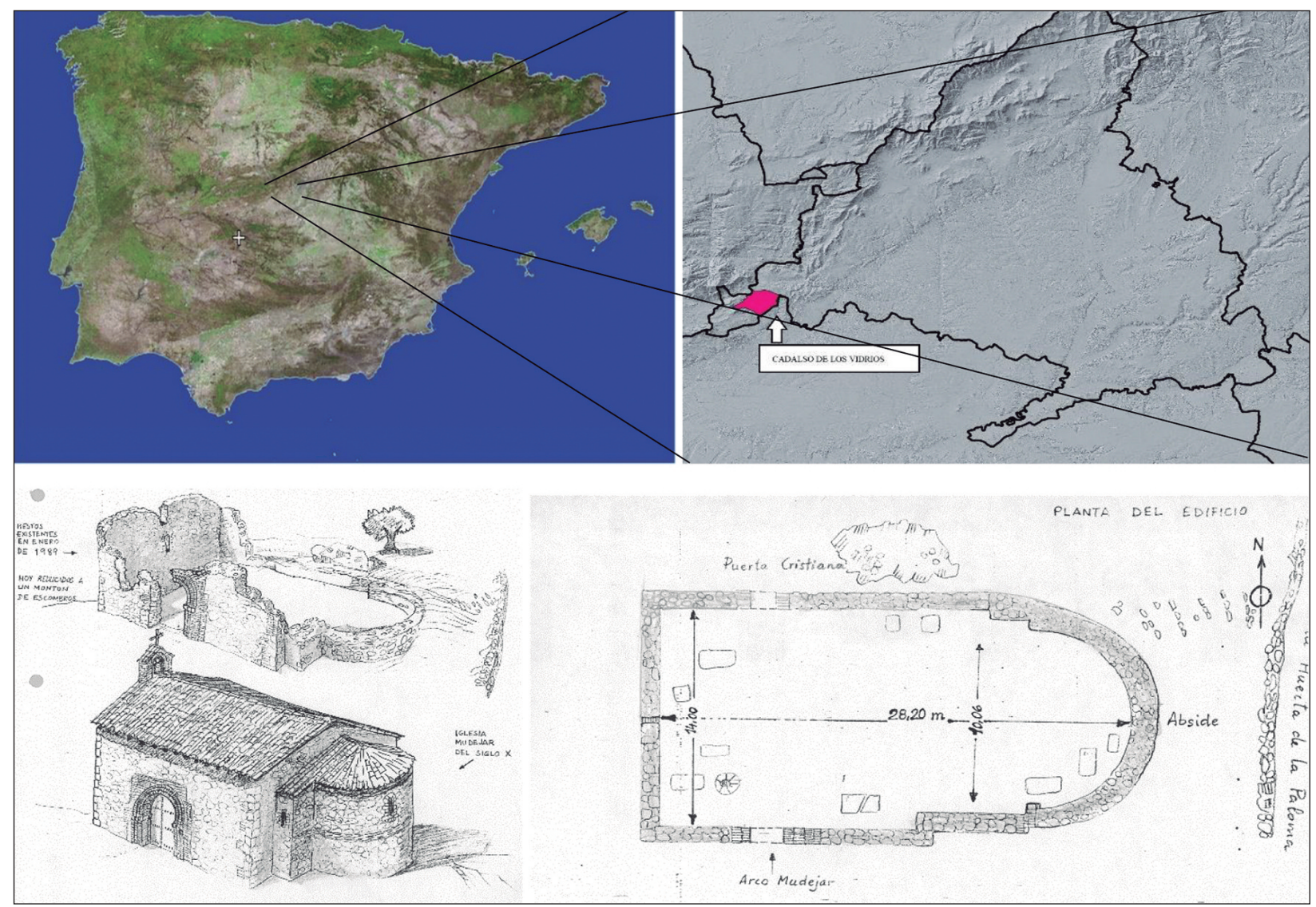

Figura 1. Situación del yacimiento, planteamiento de reconstrucción y distribución de lápidas funerarias en el interior de la nave de la iglesia.

debió ser acatada (Bango Torviso, 1992: 94), son varios los espacios sepulcrales donde hay constancia arqueológica de su rechazo (Larrea, 2016; Williams, 2010), lugares donde quizás la autoridad episcopal tuviera menor presencia (Gutiérrez Cuenca, 2019: 126). Sabemos cómo se procedía al sepelio en la Tardoantigüedad en el mundo mediterráneo (Pinar y Turell, 2007) y que esta prohibición no estaba en vigor en otros reinos cristianos como sucedía en la iglesia merovingia (Concilio de Mainz 813).

De este modo, alrededor de los edificios de culto se conformó un espacio, el atrio, de mayor o menor amplitud, dedicado al enterramiento de los difuntos. Algunos de estos espacios estaban amojonados mediante cruces, algunas de ellas con forma discoidea, que lo delimitaban (Bango Torviso, 1992: 96; Casa Martínez, Doménech y Ucla, 2016: 229233).

Este tipo de monumentos, las estelas, no sólo son propias del cristianismo, otras religiones también las usaron. Las hebreas, consisten en inscripciones fune- rarias referidas al finado (López de los Mozos, 2004: 43). En las islámicas podemos hablar de la existencia de estelas y cipos que pueden presentar alguna inscripción coránica (Juan García, 1987; Izquierdo Benito, 1979), incluso realizadas en cerámica, como las meriníes localizadas en Algeciras (Oliva, Torremocha y Martínez, 2004).

Este conjunto de estelas tiene un valor destacado puesto que son escasas los monumentos de este tipo documentados en el actual territorio de la Comunidad de Madrid. Este tipo de documentos peninsulares son bastante numerosos en otras áreas de península, destacando sobre todas, la zona del País Vasco y Navarra (Jusué y Tabar, 1995); además aparecen en otras zonas como la catalana y gran parte del área norte peninsular y zona portuguesa, donde se documentan un importante corpus que supera la 1.000 estelas. Son un tipo de monumentos que no son exclusivos de la península localizándose ampliamente en el sur de Francia y Europa central y del norte, además de la oriental y la zona del mar Egeo ${ }^{4}$.

\footnotetext{
4 Sirva como referencia de su expansión y estudio la recopilación bibliográfica sobre este tema realizada por C. de la Casa y J. Menchón (1995).
} 


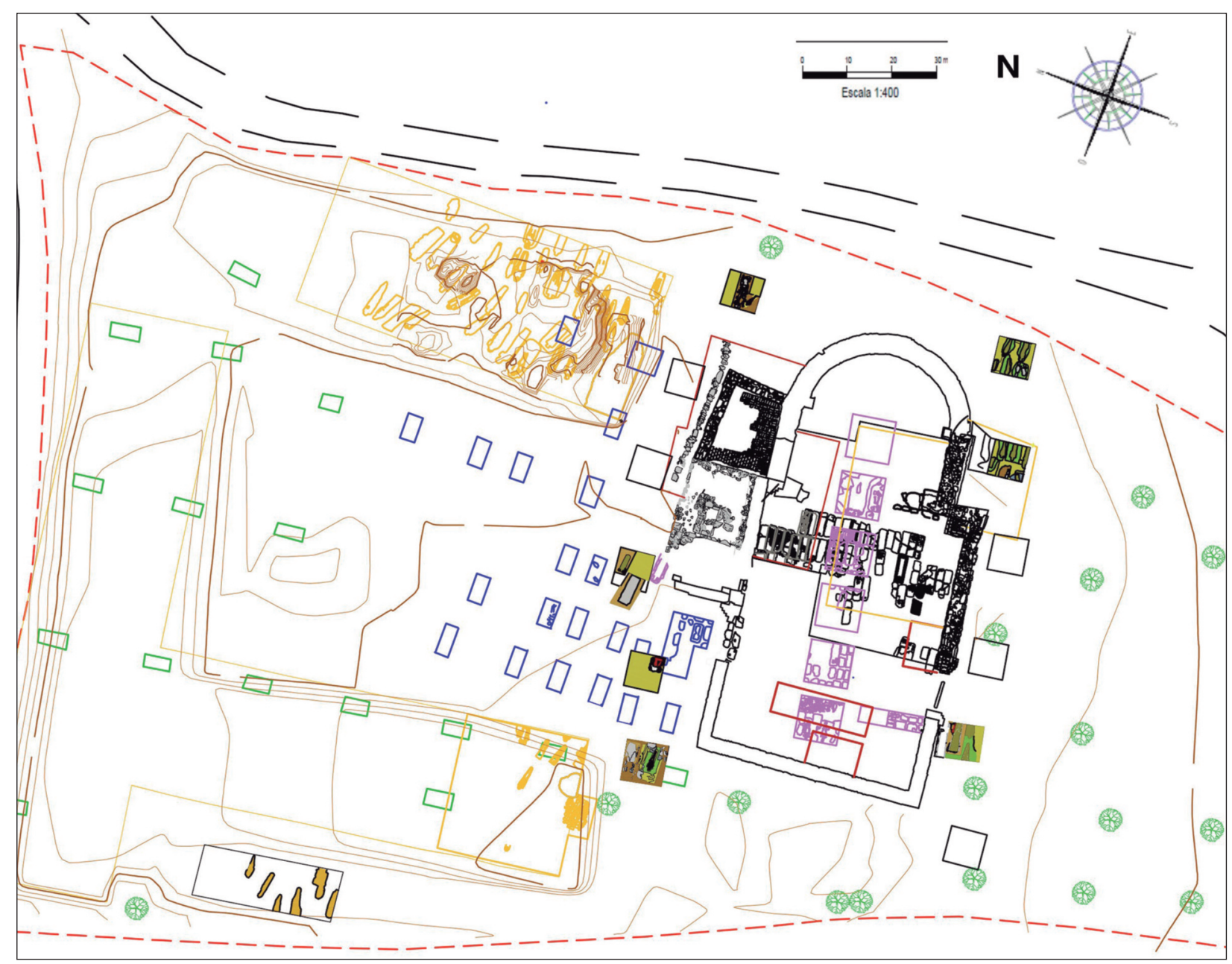

Figura 2. Planimetría de "La Mezquita" con las diferentes campañas de excavación arqueológica. (M. Crespo 2014, actualizado por E. Sanz 2017).

\section{El Yacimiento de "LA Mezquita"}

El yacimiento arqueológico se localiza en el término municipal de Cadalso de los Vidrios, en el suroeste de la Comunidad de Madrid, ubicado en la cuenca media del río Alberche. Este territorio forma parte de dos importantes dominios fisiográficos: las estribaciones meridionales del Sistema Central y la depresión del Tajo, en la zona de transición entre las Sierras de Gredos y Guadarrama. Es un espacio regado por múltiples arroyos que desaguan en el río Alberche.

En este yacimiento se han llevado a cabo diversas labores arqueológicas desde 1985 hasta prácticamente la actualidad. Ya desde las primeras intervenciones se vio su importancia al exhumarse en el interior del edificio una serie de lápidas graníticas de carácter epigráfico pertenecientes al suelo de este, además de un fragmento de brocal de pozo (Crespo Fernández, 2012: 428). En la década de los 90 , debido a la concesión de una licencia urbanística que afectaba profundamente el yacimiento, se realizaron diversas intervenciones de urgencia centradas tanto en el interior como en el exterior del edificio. En 1994 bajo la dirección de M. Contreras y S. Consuegra, se realizaron varios sondeos en el interior del edificio donde se documentó la presencia de numerosos enterramientos en realizados en fosa, cuyas cubiertas graníticas, conformaban el pavimento de la iglesia. Los estudios de paramentos llevados a cabo durante esta intervención mostraron la existencia de diferentes fases constructivas. A la primera fase correspondería la nave central de la iglesia, de planta rectangular, que se vería ampliada en una fase posterior cuando se le adosaría un ábside de planta semicircular. Recientemente se ha sugerido la posibilidad de la existencia de un edificio previo, que se podría corresponder con un templo u oratorio islámico a partir del cual, y ya en el siglo XIII, se levantaría la nave central del edificio ya cristiano (Arribas Álvarez, 2014: 85-86). 
En cuanto a los diversos espacios funerarios documentados, una primera fase o fundacional, se correspondería con la existencia de tumbas excavadas en la roca, en el substrato geológico, predominantemente antropomorfas con cabecera recta, aunque no faltan las de cabecera circular y las de tipo bañera. Para estas inhumaciones se ha establecido una cronología entre finales del siglo XI y las primeras décadas del siglo XII (Crespo Fernández, 2012: 430); estas inhumaciones situadas en la zona que ahora ocupa el ábside, no se ven afectadas por los muros del edifico primitivo, sino que su disposición parece establecida respetando el contorno de este (Arribas Álvarez, 2014: 86).

Estratigráficamente situadas sobre las tumbas excavadas, y ya correspondientes a una segunda fase de uso en la necrópolis, se situarían tumbas de mampostería que también respetan ese supuesto edificio primitivo (Crespo Fernández, 2012: 432). También con esta fase se relacionan las fosas simples en las que el difunto era inhumado en el interior de un ataúd de madera, envuelto con un sudario, que se han fechado a lo largo del siglo XIII. El conjunto de estelas discoideas documentadas se ha relacionado con estos tipos de enterramientos (tumbas excavadas en la roca y con las de mampostería), por tanto, fechadas entre los siglos XI y XIII.

$\mathrm{Y}$ una tercera fase en la que las inhumaciones se realizarían mediante lajas de granito, fosas con cubierta granítica y tumbas en ladrillo cuya cronología se ha establecido entre los siglos XIV y XV (Benito-López, García Valero, Garrido Pena, y Muñoz López-Astilleros, 1996); esta fase se correspondería por un lado con el momento de construc-

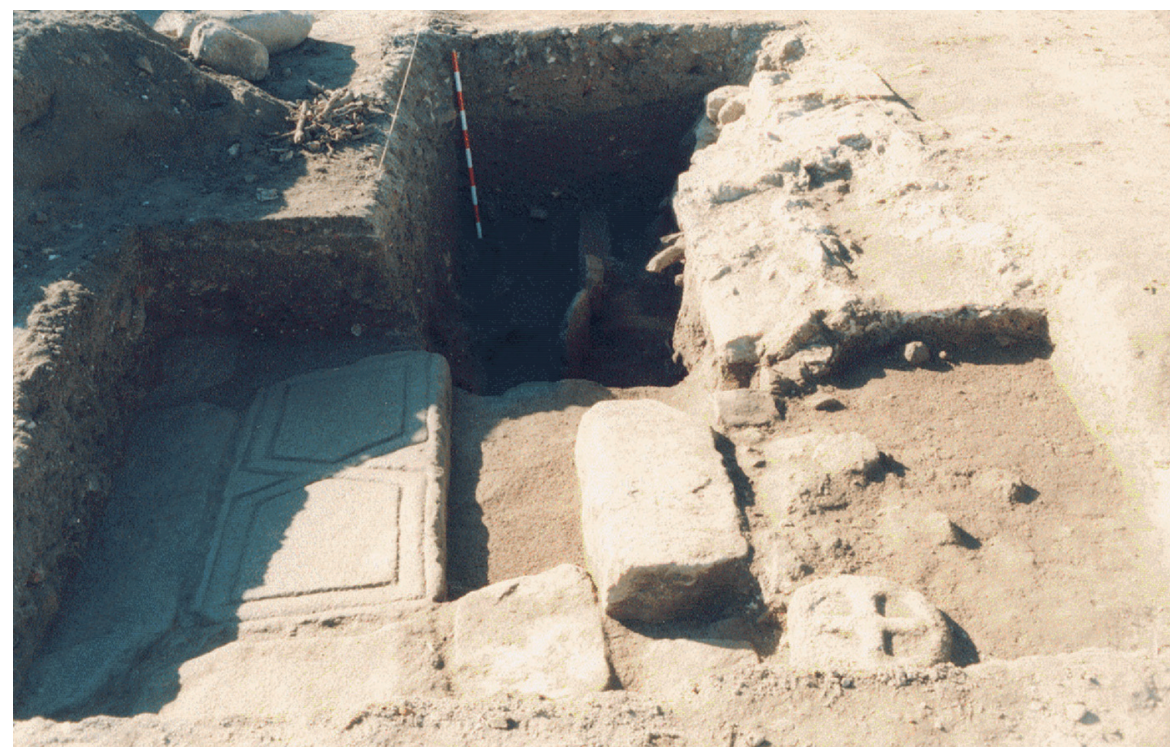

Figura 3. Detalle de la intervención arqueológica en el Área 3, año 1994 (interior de la nave central). ción del edificio actual, la construcción del presbiterio, ábside, campanario, sacristía y albañal (Crespo Fernández, 2012: 433), y, posteriormente, con el abandono del culto en la iglesia (Contreras y Consuegra, 1994).

Por otro lado, al exterior del actual edificio las excavaciones arqueológicas llevadas a cabo, mostraron la existencia la existencia de una necrópolis de enterramientos en fosa individuales (en algunas de ellas se llegaron a documentar restos de hasta tres individuos en su interior) y tumbas en fosa con cubierta granítica, como las documentadas en el interior, todas ellas con una amplia cronología -entre los siglos XIII al XIX-, ya que pese a que el abandono de la iglesia se produjo a finales del siglo XV o comienzos del XVI, la necrópolis continuó en uso (Cubero y Salvador, 1994). También junto al pórtico norte, se documenta una fosa común, con una cronología establecida entre los siglos XVI y XVII, que rompería las inhumaciones medievales anteriores (Sánchez, 1995).

\subsection{Catálogo de estelas recuperadas en el yacimiento}

A lo largo de las diferentes intervenciones arqueológicas llevadas a cabo en el yacimiento se han documentado catorce estelas discoideas. Nueve de ellas se recuperaron durante las labores de limpieza, prospección o excavación de las diferentes áreas que conforman el yacimiento, mientras que los cinco restantes se encuentran reutilizadas en los diferentes muros del edificio, como material constructivo.

Las estelas $n^{\circ} 1,2$ y 3 fueron recuperadas en las intervenciones de 1993, todas ellas en el Área 3, en el interior del actual edificio en la zona correspondiente a la nave central, con una cronología comprendida entre los siglos XI y XIII. Las estelas $\mathrm{n}^{\circ} 4,5,6$ y 7 se recuperaron en las intervenciones arqueológicas realizadas durante el año 1994, en el Área 1; esta zona se sitúa al norte del edificio de culto y localizada en su inmediato exterior, donde se documentaron un importante número de inhumaciones, con un arranque a lo 


\begin{tabular}{|c|c|c|c|c|c|}
\hline Estela & Anverso & Reverso & Descripción & Decoración & Medidas \\
\hline 1 & & & $\begin{array}{l}\text { Estele discoidea cn granito } \\
\text { claro, con pi trapezoidal } \\
\text { fragnentada }\end{array}$ & Sin decoración & $\begin{array}{l}\text { Diammetro: } 30 \mathrm{~cm} \\
\text { Espesor: } 12 \mathrm{~cm} \text { Alt. } \\
\text { totat } 47 \text { cm. Anc. base: } \\
28 \mathrm{~cm}\end{array}$ \\
\hline 2 & & & $\begin{array}{l}\begin{array}{l}\text { Esteleh discoidea en granito } \\
\text { claro, de fondo rebajado, } \\
\text { pie desaparecido, } \\
\text { fragnentada }\end{array}\end{array}$ & $\begin{array}{l}\text { Anverso: Cruz ancorada de brazos } \\
\text { rectos exentos con la bordura, de } \\
\text { anchura constante. } \\
\\
\text { Reverso: Cruz ancorada de brazos } \\
\text { rectos exentos con la bordura, de } \\
\text { anchura constante. }\end{array}$ & $\begin{array}{l}\text { Dïmetro: } 42 \mathrm{~cm} \\
\text { Espesor: } 16 \mathrm{~cm} \text { Alt. } \\
\text { total: } 38 \mathrm{~cm}\end{array}$ \\
\hline 3 & & & $\begin{array}{l}\text { Estela discoidea en granito } \\
\text { claro, de fondo rebajado, } \\
\text { pie desaparecido, } \\
\text { fiagnentada }\end{array}$ & 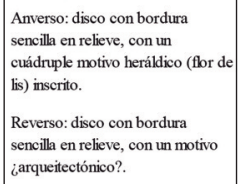 & $\begin{array}{l}\text { e Dämetro: } 33 \mathrm{~cm} \\
\text { Espesor } 13 \mathrm{~cm} \text { Alt. } \\
\text { total } 25 \mathrm{~cm}\end{array}$ \\
\hline 4 & & & $\begin{array}{l}\text { Estela discoidca en grantito } \\
\text { claro, de fondo rebajado, } \\
\text { con pie apuntado. }\end{array}$ & $\begin{array}{l}\text { Anverso: cruz griega potenzzada } \\
\text { con un punto inciso en h } \\
\text { intersección de los brazos. }\end{array}$ & 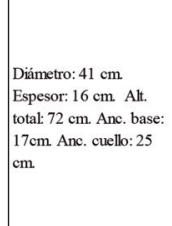 \\
\hline 5 & & & $\begin{array}{l}\text { Estela discoidea en granito } \\
\text { oscuro, de fondo rebajado } \\
\text { pie desaparecido. }\end{array}$ & $\begin{array}{l}\text { Anverso: crue griega potenzada } \\
\text { con un punto inciso en la } \\
\text { intersección de los brazos. } \\
\text { Reverso: sin decoración. }\end{array}$ & $\begin{array}{l}\text { Diametro: } 34 \mathrm{~cm} \\
\text { Espesor: } 11 \mathrm{~cm} \text { Alt. } \\
\text { total } 37 \mathrm{~cm} .\end{array}$ \\
\hline 6 & & & $\begin{array}{l}\begin{array}{l}\text { Estela discoidea en granito } \\
\text { oscuro, de fondo rebajado } \\
\text { pie desaparaceido, } \\
\text { fragnentada }\end{array} \\
\end{array}$ & $\begin{array}{l}\text { Anverso: cruz ancorada de brazos } \\
\text { rectos exentos con la bordura. En } \\
\text { Reverso: cruz ancorada de brazos } \\
\text { rectos exentos con l bordura. }\end{array}$ & $\begin{array}{l}\text { Dímetro: } 34 \mathrm{~cm} \\
\text { Espessor } 8 \mathrm{~cm} \text {. Alt. } \\
\text { total } 29 \mathrm{~cm}\end{array}$ \\
\hline 7 & & & $\begin{array}{l}\text { Estelea discoidea en granito } \\
\text { claro, de fondo rebajado, } \\
\text { pie desaparecilo. }\end{array}$ & $\begin{array}{l}\text { Anverso: cruz grigga con brazos } \\
\text { reetos hasta la bordura. } \\
\text { Reverso: cruz griega con brazos } \\
\text { rectos hasta la bordura. }\end{array}$ & $\begin{array}{l}\text { Dänetro: } 36 \mathrm{~cm} \\
\text { Espesor: } 10 \mathrm{~cm} \text { Alt. } \\
\text { total } 32 \mathrm{~cm}\end{array}$ \\
\hline 8 & & & $\begin{array}{l}\text { Estela discoidea en granito } \\
\text { claro, de fondo rebajado. }\end{array}$ & $\begin{array}{l}\text { Anverso: cruz de Malta con los } \\
\text { brazos exentos, cuyo brazo } \\
\text { superior está formado a su vez por } \\
\text { una cruz ensanchada de brazos } \\
\text { abocinados y extremos rectos. } \\
\text { Reverso: cruz latina }\end{array}$ & 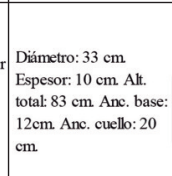 \\
\hline 9 & & & $\begin{array}{l}\text { Estela discoidea de fondo } \\
\text { rebajado, pie desaparecidd } \\
\text { fragmentada. }\end{array}$ & $\begin{array}{l}\text { Anverso: crnz flordelizada. } \\
\text { Reverso: sin decoración }\end{array}$ & $\begin{array}{l}\text { Dhïmetro: } 26 \mathrm{~cm} \\
\text { Espesso: } 12 \mathrm{~cm} \text { Alt. } \\
\text { total: } 12 \mathrm{~cm}\end{array}$ \\
\hline 10 & & & $\begin{array}{l}\text { Estela discoidea en granito } \\
\text { claro, de fondo rebajado } \\
\text { con el pie roto. }\end{array}$ & $\begin{array}{l}\begin{array}{l}\text { Anverso: cruz grigga de brazos } \\
\text { rectos. }\end{array} \\
\text { Reverso: desconocido }\end{array}$ & $\begin{array}{l}\text { Diametro: } 36 \mathrm{~cm} \text {. Alt. } \\
\text { total } 55 \text { cm Anc. base: } \\
22 \mathrm{~cm} \text { Anc. cuelolo: } 23 \\
\mathrm{~cm}\end{array}$ \\
\hline 11 & & & \begin{tabular}{|l} 
Estele discoidea en granito \\
charo, con el pie apuntado.
\end{tabular} & $\begin{array}{l}\text { Anverso: sin decoración. } \\
\text { Reverso: desconocido. }\end{array}$ & $\begin{array}{l}\text { Dämetro: } 33 \mathrm{~cm} \text {. Alt. } \\
\text { total } 75 \text { m Anc. base: } \\
20 \mathrm{~cm} \text { Anc. cuelo: } 23 \\
\text { cm. }\end{array}$ \\
\hline 12 & & & \begin{tabular}{|l} 
Estela discoidea en granito \\
claro, con el pie \\
desapareceilo, fragnentadada
\end{tabular} & $\begin{array}{l}\text { Anverso: sin decoración. } \\
\text { Reverso desconocido. }\end{array}$ & $\begin{array}{l}\text { Diámetro: } 26 \mathrm{~cm} \\
\text { Espesor: } 6,5 \mathrm{~cm} \text { Alt. } \\
\text { total } 20 \mathrm{~cm}\end{array}$ \\
\hline 13 & & & $\begin{array}{l}\text { Estela discoidea en granito } \\
\text { claro, fragnentada, con el } \\
\text { pie, de base amplia junto a } \\
\text { ela }\end{array}$ & $\begin{array}{l}\text { Anverso: sin decoración. } \\
\text { Reverso: desconocido. }\end{array}$ & $\begin{array}{l}\text { Diammetro: } 32 \mathrm{~cm} \\
\text { Espesor: } 9 \mathrm{~cm} \text { Alt. } \\
\text { totat } 66 \text { o cm Anc. base: } \\
26 \mathrm{~cm}\end{array}$ \\
\hline 14 & & & $\begin{array}{l}\text { Estela discoidea en granito } \\
\text { charo, con clpip } \\
\text { desaparecido, fragmentada }\end{array}$ & $\begin{array}{l}\begin{array}{l}\text { Anverso: sin decoración, tene una } \\
\text { pequeña hendidura rectangular en } \\
\text { su parte central }\end{array} \\
\text { Reverso: desconocido. }\end{array}$ & $\begin{array}{l}\text { Dëmetro: } 32 \mathrm{~cm} \\
\text { Especsor: } 11 \mathrm{~cm} \text { Alt. } \\
\text { totat } 25 \mathrm{~cm}\end{array}$ \\
\hline
\end{tabular}

largo del siglo XIII. Las estelas $n^{\circ} 8$ y 9 , se documentaron en 1995 también en el Área 1.

Las estelas $\mathrm{n}^{\circ} 10$ y 11 , se encuentran reutilizadas en el muro sur de la nave central en las proximidades de la puerta meridional de la iglesia, posiblemente situadas allí cuando se levantó este muro durante la ampliación del edificio, posiblemente a lo largo del siglo XIII (Arribas Álvarez, 2014: 8687); esta localización nos hace pensar que se han desplazado de un lugar inmediato, y que posiblemente, estuvieran situadas al exterior del posible edificio primitivo, y con la ampliación y construcción de los nuevos muros, fueran allí reutilizadas como material constructivo. Por su parte, las estelas $\mathrm{n}^{\circ}$ 12,13 y 14 se encuentran en la parte superior de los muros que conforman la sacristía; la ${ }^{\circ} 12$ en el muro norte y las otras dos en el muro este. Estas tres estelas debieron ser colocadas en su nuevo emplazamiento en el momento de la construcción de la sacristía, posiblemente entre los siglos XIV o XV (Arribas Álvarez, 2014: 86), pero siempre en un momento posterior a la construcción de la nave central del edifico de culto.

Estas cinco estelas, $\left(\mathrm{n}^{\circ} 10\right.$ a 14) son visibles en la actualidad, situándose en la cara superior de los correspondientes muros; su localización permite pensar que en los alzados de los muros de la iglesia se pudieran encontrar más estelas reutilizadas como material constructivo y que no estuvieran visibles o hubieran desparecido cuando, con el paso del tiempo y diversas vicisitudes estos muros fueran colapsando.

Figura 4. Catálogo de las estelas recuperadas en el yacimiento 


\subsection{Análisis tipométrico e iconográfico de las estelas}

Una vez analizado el conjunto de estelas podemos establecer una serie de conclusiones preliminares. El conjunto de estelas documentado se presenta bastante homogéneo, son pequeñas las variaciones que se observa en los tamaños de estas. La principal diferencia que podemos establecer es en cuanto a la decoración que presentan, mientras que una parte importante de estas presenta algún tipo de ornamentación, otras se presentan sin ella, es decir anepígrafas.

Las diferentes medidas que nos proporciona este conjunto no se alejan de las referenciadas en otras zonas peninsulares. En cuanto a las alturas totales, en aquellas que se ha podido constatar, se encuentran entre los 55 y $75 \mathrm{~cm}$, mientras que los diámetros totales aproximados deben encontrarse entre los 26 y $36 \mathrm{~cm}$. En cuanto al grosor del disco nos encontramos ante algunas estelas con un importante grosor, con $16 \mathrm{~cm}$, mientras que otras se tan solo alcanzan $\operatorname{los} 7 \mathrm{~cm}$.

En general, la estética de las estelas se ve fuertemente condicionada por el material elegido; en este caso todas ellas están realizadas en granito claro de grano fino, salvo las $n^{\circ} 5$ y 6 , que presentan un granito de tonalidad más oscura. Esta piedra posiblemente proviene de canteras locales; estos filones graníticos se encuentran no muy alejados de la localidad de Cadalso y durante estos siglos han sido utilizados como material constructivo y soporte epigráfico como se puede observar en otras lápidas funerarias que se encuentran en el mismo yacimiento o en muchos de los dinteles con decoración que se encuentran en las casas del municipio.

En algunas de las piezas analizadas no se ha podido documentar una de sus caras porque están amortizadas como elementos constructivos en los muros del edificio de la iglesia. Esta circunstancia no permite conocer si esa cara que hoy en día se encuentra oculta puede presentar algún tipo de decoración. Llama la atención que al menos tres de las estelas que no presentan decoración se sitúan en los muros de la sacristía, edificio que se sitúa al norte de la nave principal y que fue construido con posterioridad a esta, con lo que podemos pensar que estas estelas procedían de las tumbas que se encuentran en la necrópolis exterior, al norte del edifico con una cronología establecida a partir del siglo XIII (Cubero y Salvador, 1994). Otra de las estelas anepígrafas está localizada en el muro sur de la nave central y la otra fue documentada en el interior de la nave central, pero respetando el contorno de ese posible edificio primitivo.

Estas estelas sin decoración son piezas simples, donde es la propia forma del monumento el que acapara el protagonismo. En todas ellas las superficies se presentan muy bien trabajadas y alisadas. En el caso de la $n^{\circ} 14$ presenta en el anverso y una hendidura de forma rectangular situada en la parte central del disco desconociéndose su utilidad 5 . Por su inherente simplicidad, este tipo de estelas a menudo pasan desapercibidas o suelen ser puestas en duda; por este motivo, su número total puede ser muy superior al actualmente conocido. Existen estelas semejantes en muchos lugares de la península ${ }^{6}$. En cuanto a su función debía ser simplemente indicativa de la presencia de la sepultura sin proporcionar ninguna información complementaria.

La iconografía que aparece en las estelas presenta una estricta simetría en la decoración. La mayor parte de las estelas con decoración presentan una orla o bordura que refuerza visualmente el disco exteriormente, algo por otro lado muy habitual en multitud de estelas. Algunas de ellas presentan un punto central de mayor o menor tamaño que podría haber sido utilizado para organizar la decoración o para otro fin hoy desconocido. Todas las representaciones están realizadas en bajorrelieve, es decir, rebajando el contorno de la figura que se quiere representar y, de este modo, el motivo y la orla que lo rodea quedan a mayor altura que el resto de la pieza. Los cantos de los discos de las todas estas piezas aparecen lisos, sin ningún tipo de decoración, como pueden aparecer en otras piezas.

Centrándonos en las nueve piezas que presentan decoración como no podía ser de otro modo el símbolo predominante son las cruces en sus diversas

\footnotetext{
5 Paralelos similares podemos encontrar en la estela $n^{\circ} 1$ procedente de Villavelayo (Pascual Mayoral y Pascual Mayoral, 1999:325).

6 Entre otros muchos podemos citar: cuatro estelas en la zona de Barco de Ávila (González Calle, Mayoral Castillo, y Savirón Cuartango, 2009: 178); cinco estelas procedentes de la iglesia de la Sangre (Lliria, Valencia) (Bonet Rosado y Marimón Martín, 1986: 67, 69, 73); catorce estelas procedentes de Andaluz (Soria), inventariadas por Casa Martínez y Doménech (1983b: 4345, 47-48); tres procedentes de Tiermes y una de Renieblas (Soria) (Casa Martínez y Doménech Esteban 1983b: 86, 88, 105, 108-109, 113, 115) y una localizada en Agejas (Segovia) (Casa Martínez y Doménech Esteban, 1986: 308).
} 
formas; no debemos olvidar que es el principal motivo del cristiano, por lo que es habitual que sea el más representado en las estelas medievales.

De este modo las estelas $\mathrm{n}^{\circ} 2$ y 6 presentan en ambas caras cruces griegas ancoradas ${ }^{7}$. Las estelas $n^{0}$ 4 y 5 presentan cruces griegas potenzadas 8 ; pero mientras que la número 4 presenta sendas cruces en ambas caras, el reverso de la $\mathrm{n}^{\circ} 5$ aparece sin decoración. Otro modelo de cruces griegas son las que presenta la estela $\mathrm{n}^{\circ} 7^{9}$ en ambas caras; motivo similar al que presenta el monumento $\mathrm{n}^{\circ} 10$ en el anverso mientras que el reverso es desconocido. Este tipo de cruz, la griega, con brazos con longitudes similares son las más comunes, puesto que son las más fáciles de insertar dentro de la orla o círculo. Por su parte, las que se presentan ancoradas se han relacionado con la esperanza en Cristo y la salvación del alma (Becker, 1996; Pérez, 1997).

La estela $n^{\circ} 8$ presenta una decoración que difiere del resto del conjunto. En el anverso presenta una cruz de Malta bifurcada ${ }^{10}$ en la que el brazo superior ha sido sustituido por una cruz latina ensanchada de brazos abocinados, mientras que el reverso presenta una cruz latina. Hay que decir que la cruz de Malta es un símbolo utilizado a partir del siglo XII como insignia de los caballeros sanjuanistas u hospitalarios.

La estela $\mathrm{n}^{\circ} 9$ presenta en el anverso una cruz flordelisada ${ }^{11}$ mientras que el reverso aparece sin decoración. Las cruces latinas tienen brazos rectos, con mayor longitud en el inferior. En general, estas cruces aparecen con menor frecuencia en las estelas discoideas, ya que su diseño se adapta peor al disco. En cuanto a la cruz flordelisada a veces se ha relacionado con la orden de Montesa (Casa, Doménech, y Menchón, 1994: 208). Por otro lado, la flor de lis es la flor de María (Pérez, 1997) y representa la pureza, destacando los tres pétalos en recuerdo de la Trinidad (Becker, 1996).

Por otro lado, la estela ${ }^{\circ} 3$ presenta en el anverso cuatro flores de lis ${ }^{12}$ de pequeñas dimensiones dispuestas en dos filas de dos elementos y en el reverso un motivo arquitectónico, que consideramos heráldico más que referencia a una ocupación (constructor), y que al estar fragmentado no llegamos a identificar, pero bien podría tratarse de una arcada, edificio o puente. Estos elementos ${ }^{13}$, pueden representar los arcos y decoraciones arquitectónicas de los claustros románicos y góticos, con los que posiblemente guarden relación (Tabar Sarrías, 1993: 180181). Los motivos heráldicos aparecen con menor frecuencia en la decoración de las estelas, posiblemente por ser un elemento relacionado con la alta sociedad; Suelen aparecer en lugares de enterramiento de personajes de cierta categoría, como los monasterios de las Huelgas (Casa, Doménech, y Menchón, 1994) o Poblet (Cabestany, 1983: 265274). La flor de lis como único elemento representado aparece pocas veces; es muy común en las estelas documentadas en el Monasterio de las Huelgas (Casa, Doménech, y Menchón, 1994: 208).

A través del análisis de los motivos decorativos podemos extraer algunas conclusiones, entre ellas hay algunos motivos que podrían sugerir la presencia de personajes relacionados con algunas de las diferentes Ordenes Militares y, por otro lado, motivos relacionados con personajes de la alta sociedad como en algunos casos lo son los heráldicos.

Como decimos la homogeneidad del conjunto, de los motivos decorativos y del material utilizado, permite pensar en la posible existencia de un taller local donde se elaboraran las mismas.

\section{RELACIÓN CON OTROS EJEMPLOS EXISTENTES EN LA SierRa DE GUADARRAMA}

Como decíamos anteriormente, son escasos los ejemplos de estelas situadas en el territorio madrileño, las conocidas se sitúan en el piedemonte serrano, en la cara meridional Sistema Central. Pese

\footnotetext{
7 Con paralelos en las estelas $n^{\circ} 1,16$ y 27 (Tabar Sarrías, 1993: 93, 115-116 y 128).

8 Similares motivos encontramos en la estela no 2 en Arguíroz, con múltiples paralelos (Tabar Sarrías, 1993: 95-96).

9 Paralelos encontramos en Madrigalejo del Monte (Ramos Benito, 2012: 811), o la estela nº 1 de Almazán (Casa y Doménech, 1994: 222).

10 Paralelos a esta se encuentran en zonas del Tera.

11 Conocemos paralelos en la estela $\mathrm{n}^{\circ} 7$ del Monasterio de Villamayor de los Montes (Burgos) (Campillo Cueva, 2006: 437 438), o las estelas $\mathrm{n}^{\circ}$ 1, 8, 13, 1415 y 16 del Monasterio de las Huelgas (Burgos) (Casa, Doménech, y Menchón, 1994: 196201).

12 Paralelos podemos encontrar en las estelas no 3, 8 y 10 (Casa, Doménech, y Menchón, 1994: 197-199, 201).

${ }^{13}$ Se conocen algunos paralelos como en los ejemplares $n^{\circ} 23$ de Estella, $n^{\circ}$ de Iranzu y en otros de procedencia desconocida de esta misma colección (Tabar Sarrías, 1993: 180-181).
} 
al escaso número conocido debemos suponer que podría ser mucho mayor teniendo en cuenta las documentadas en territorios próximos. Es de suponer que una intensificación en la investigación sobre estos elementos incrementaría notablemente su número.

Entre las conocidas, una se encontraba en la plaza de la iglesia de Lozoya, realizada en caliza, presentaba en ambas caras una estrella de ocho puntas (Frankowski, 1920), a día de hoy está desparecida. Otra se localiza en una tapia del municipio de Guadarrama, con un motivo en bajorrelieve, sin bordura, y consisten en una cruz patada con brazos curvilíneos, de la estela solo se observa una cara (Pozuelo Ruano, 2009: 32).

Frente a la iglesia de Manzanares el Real se encuentra un conjunto de cuatro estelas, todas ellas con decoraciones a base de cruces patadas en bajorrelieve, con bordura, presentándose el motivo en ambas caras y una estela documentada en un jardín particular con una cruz griega con bordura en ambas caras (Pozuelo Ruano,

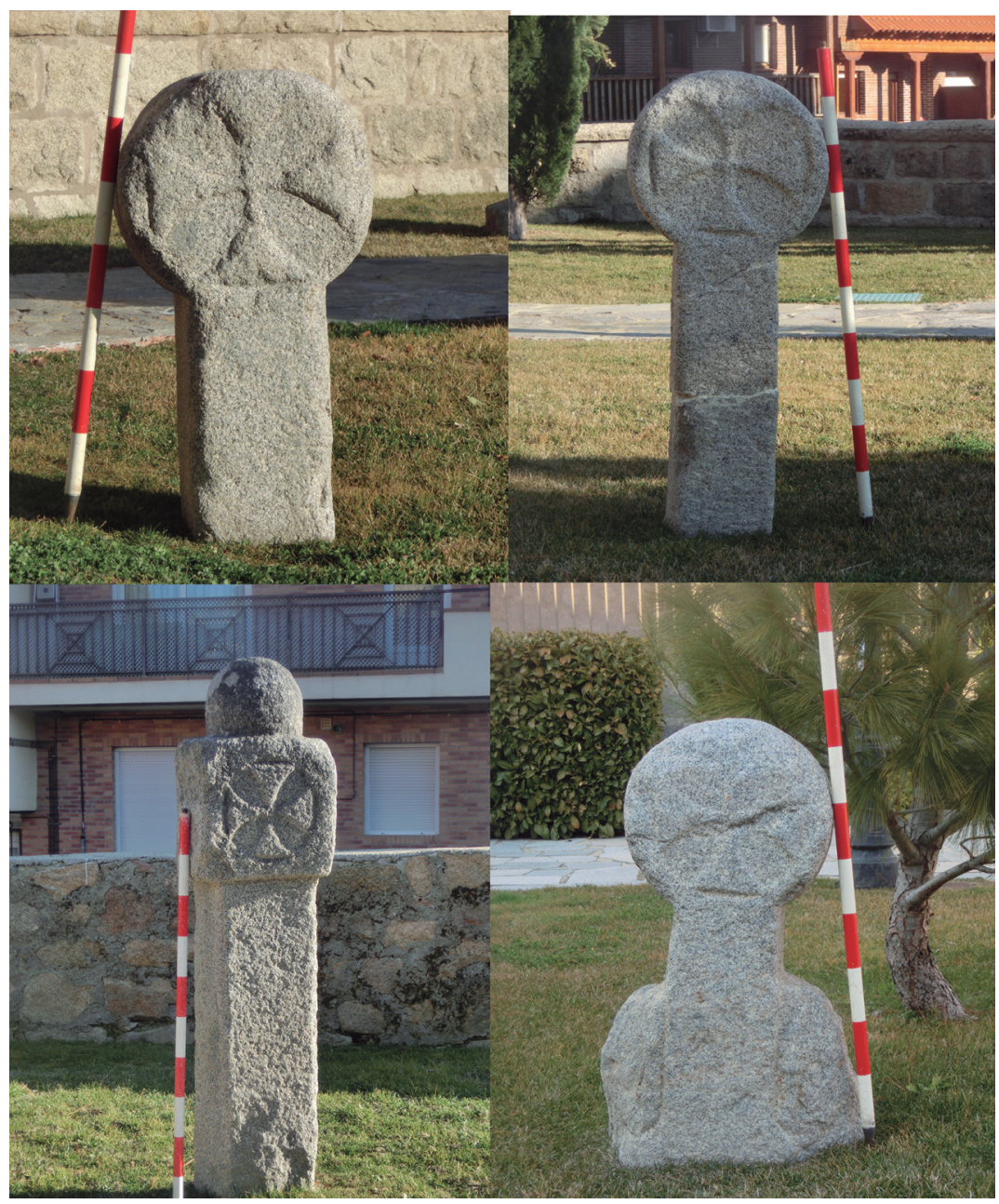

Figura 5. Conjunto de estelas situadas junto a la iglesia parroquial de Manzanares el Real (Madrid). 2009: 20-25). Estas se han fechado entre los siglos XII-XIV. Otro ejemplo posible se encuentra en la ermita de Nuestra Señora de los Remedios en Colmenar Viejo, aunque esta estela aparentemente no es discoidea y a diferencia de las anteriores su decoración se realiza mediante grabado (Hernández Sousa, 2016).

\section{Conclusiones}

Como hemos dicho anteriormente son escasos, por el momento, el número de ejemplares conocidos en estos territorios madrileños; todos ellos situados en zonas serranas, en el piedemonte, en territorios relacionados con la explotación ganadera, en los que destaca la presencia del granito como roca más destacada.

En cuanto a las cronologías establecidas, mientras que en las situadas más al norte, se fechan entre los siglos XII y XIV, salvo la situada en Colmenar Viejo, que presenta otras características, podría tener una cronología algo anterior. Por su parte las presentadas en este catálogo, pese a no poder establecer una cronología más precisa, podrían ser fechadas por el contexto arqueológico en el que aparecieron entre los siglos XI y XIII.

Sabemos, a través de las excavaciones arqueológicas realizadas en algunos espacios cementeriales castellanos que la mayoría de las sepulturas no debían estar señalizadas mediante estelas discoideas ${ }^{14}$. Esto mismo sucede en este yacimiento, donde se han documentado más de un centenar de

\footnotetext{
${ }^{14}$ En el cementerio de San Juan de los Caballeros (Segovia) de un total de 33 sepulturas, datadas en los ss. XI-XIII, tan solo una tumba contaba con dos estelas discoideas señalando sus extremos. Lo mismo sucede en este yacimiento de Cadalso de los Vidrios, de las más de un centenar de inhumaciones localizadas tan sólo contamos con catorce ejemplares.
} 


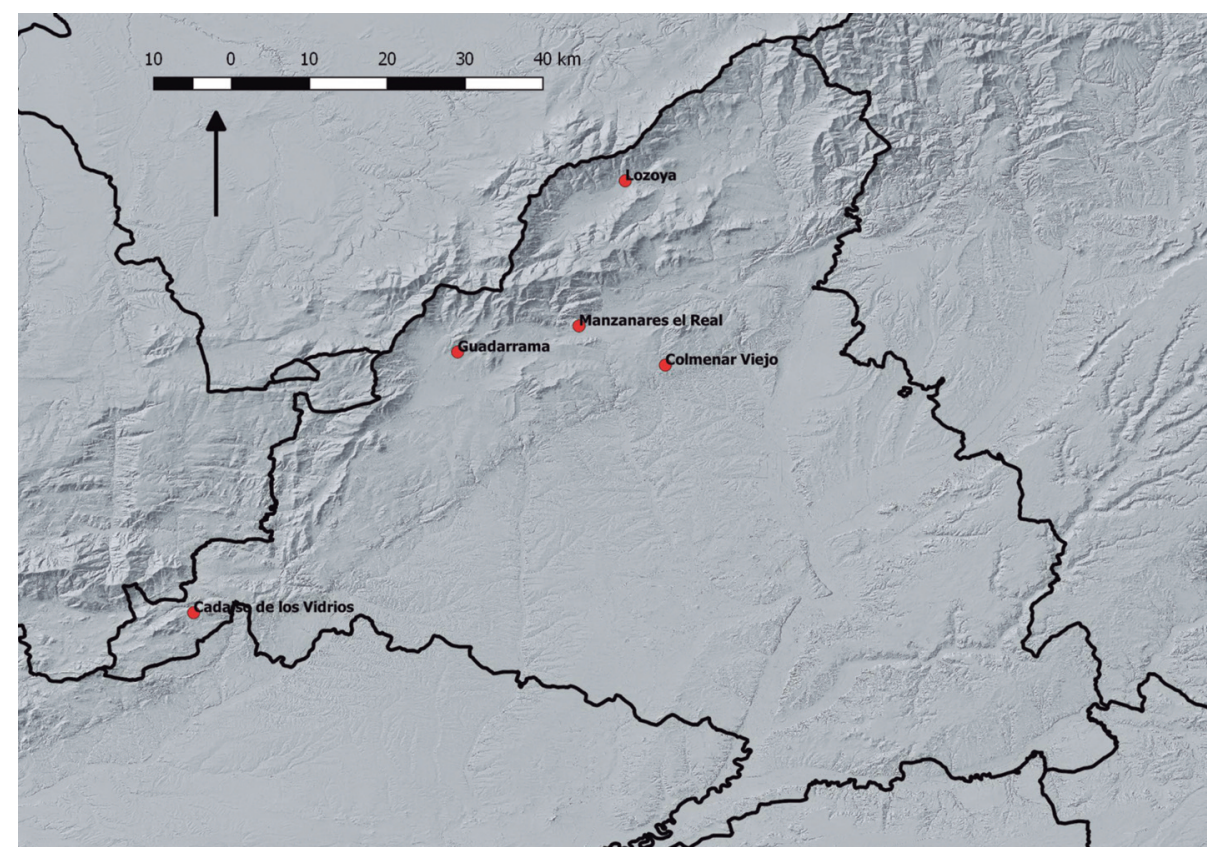

Figura 6. Situación de las estelas conocidas en la cara meridional de la Sierra de Guadarrama. la necesidad de indicar donde se encuentra una sepultura y a quien pertenece. Cuando se produjeron enterramientos en el interior edificio de culto, proliferaron otros monumentos como fueron las lápidas sepulcrales en las que se indicaban los datos de los ocupantes de las sepulturas.

A partir de la segunda mitad del siglo XIII y sobre todo a lo largo del siglo XIV se produjo un desinterés por el uso de las estelas quizás motivado por la licencia que concedió Gregorio IX para que todos los cristianos pudiesen enterrarse dentro de las iglesias (Campillo, 2006: 445). A partir de estos momentos, cuando este tipo de monumento ya han caído en desuso y la memoria de los inhumados se ha perdido, o bien motivado por las transformaciones en el edificio de culto, son reaprovechadas como material constructivo en los nuevos muros que se están erigiendo

\section{Bibliografía}

Aguirre Sorondo, A. (1989): "Una teoría sobre el origen de las estelas discoidales". III Congreso de Arqueología Medieval Española: 506-511, Oviedo.

Andrio Gonzalo, J. (1989): "Estelas de la necrópolis medieval de Palacios de la Sierra (Burgos)". III Congreso de Arqueología Medieval Española: 526-533, Oviedo.

Arribas Álvarez, F. J. (2014): La ermita de la encomienda de San Antonio Abad (Cadalso de los Vidrios, Madrid). Una propuesta metodológica de Arqueología de la Arquitectura. Trabajo Fin de Máster. Inédito. Universidad Autónoma de Madrid.

Bango Torviso, I. (1992): "El espacio para enterramientos privilegiados en la arquitectura medieval española". Anuario del Departamento de Historiay Teoría del Arte (U.A.M.) Vol. IV: 93-132.

Becker, U. (1996). Enciclopedia de los símbolos. Barcelona.

Benito-López,J., García Valero, M., Garrido Pena, R., y K. Muñoz López-Astilleros (1996): "La necrópolis medieval de "La Mezquita" (Cadalso de los mientos dentro de los edificios de culto, y, con ello, 
Vidrios, Madrid): Resultados de la última campaña de excavación". Estudios de Prehistoria y Arqueología Madrileñas 10: 121-129.

Bohigas Roldán, R., Molinero Arroyabe, J., Sarabia Rogina, P., y M. García Alonso (1989): “Aportación al corpus de las estelas discoidales de Cantabria (Edades Media y Moderna". III Congreso de Arqueología Medieval Española: 519-525, Oviedo.

Bonet Rosado, H., y J. Marimon Martin (1986): "Excavaciones en la iglesia de la Sangre de Lliria (Valencia). Campana 1984", I Congreso de Arqueología Medieval Española vol. V: 57-78, Zaragoza.

Caballero Zoreda, L. (1980): "Las cruces caladas con laurea y pie para hincar de época visigoda en España". Homenaje al Cardenal E. Tarancón: 85-102, Madrid.

Cabestany, J. F. (1983): "Estels del Museu del Monestir de Poblet (ss. XII-XIV)". Acta Historica et Archaeologica, 4: 265-274.

Campillo Cueva, J. (2006): "Las estelas medievales del monasterio cisterciense de Villamayor de los Montes (Burgos)". Boletín de la Institución Ferrán González, 233: 431-451.

Casa Martínez, G., y M. Doménech Esteban (1983a): "Estelas discoideas medievales en Campisábalos (Guadalajara)". Wad-al-Hayara: Revista de estudios de Guadalajara, 10: 397-406.

Casa Martínez, C., y M. Doménech Esteban (1983b): Estelas medievales de la provincia de Soria. Soria.

Casa Martínez, G., y M. Doménech Esteban (1986): "Aportación al corpus de estelas medievales en Castilla: Segovia". Actas del I Congreso Arqueología Medieval Española, vol. IV: 307-319, Huesca.

Casa Martínez, C., y M. Doménech Esteban (1994): "La estela funeraria hispano cristiana". V Congreso Arqueología Medieval Española, vol. 2: 445-461, Soria.

Casa Martínez, C., Jusué Simonena, C., y J. Menchón i Bes (1989): "Estelas medievales cristianas de la península ibérica". III Congreso de Arqueología Medieval Española, vol. I: 237-254, Oviedo.

Casa Martínez, G., y M. Doménech Esteban (1994): "Estelas Medievales de la Provincia de Soria II". Cuadernos de Sección. Antropología-Etnografia, 10: 219246.

Casa Martínez, C., Doménech, M., y J. Menchón (1994): "Estelas medievales del Monasterio Cisterciense de Las Huelgas de Burgos". Cuadernos de Sección. Antropología-Etnografia 10: 193-214.

Casa Martínez, C., y J. Menchón i Bes (1995): "Recopilación bibliográfica sobre estelas funerarias medie- vales y postmedievales". Cuadernos de etnología y etnografia de Navarra 65: 191-226.

Casa Martínez, C., Doménech Esteban, M y P. Ucla (2016): "Espacio funerario en el medievo: las cantigas y Renieblas (Soria, España)". Oppidum: cuadernos de investigación, 12: 219-244.

Contreras, M., y S. Consuegra (1994): "Intervención arqueológica en la Iglesia mudéjar de Cadalso de los Vidrios (Madrid)". Revista del Ilustre Colegio Oficial de Doctores y Licenciados en Filosofia y Letras y en Ciencias de Madrid, 55, XII-XIII.

Crespo Fernández, M. (2012): “Aproximación al estudio del yacimiento arqueológico de "La Mezquita" (Cadalso de los Vidrios, Madrid): nuevas aportaciones científicas". Estrat Crític 5 (2): 426-434.

Cubero, T., y A. Salvador (1994): Memoria de intervención arqueológica en la iglesia mudéjar de Cadalso de los Vidrios (Madrid). (Inédito). Dirección General de Patrimonio de la Comunidad de Madrid.

Frankowski, E. (1920): Estelas discoideas de la península Ibérica. Madrid.

Gallart ,J., y A. Llusá (2004): "Aportaciones al inventario de las estelas discoidales de las comarcas del Segre, les Garriges y el Pla d'Urgell (Lérida)". Actas del VII Congreso Internacional de Estelas Funerarias, vol. III: 965-994, Santander.

García Guinea, M. Á. (2004): "Apertura del VII Congreso Internacional de Estelas Funerarias". Actas del VII Congreso Internacional de Estelas Funerarias: 19-30, Santander.

González Calle, J., Mayoral Castillo, Á., y M. Savirón Cuartango (2009): "Estelas funerarias medievales en la comarca de El Barco de Ávila". Territorio, Sociedady Poder, 4: 167-192.

Gutiérrez Cuenca, E. (2019): "Ruptura y continuidad. Origen y evolución de los espacios funerarios medievales en el sur de Cantabria". Revista Onoba, 7: 113-131, https://doi.org/10.33776/onoba. v7i0.3627.

Hernández Sousa, J. M. (2016): "Una estela medieval en la Ermita de Ntra. Sra. de los Remedios (Colmenar Viejo)". Revista de Investigación Cuadernos de Estudio, 30: 103-116.

Izquierdo Benito, R. (1979): "Excavaciones de la ciudad hispano-musulmana de Vascos. Campañas de 1975 y 1978". Noticiario Arqueológico Hispano, 7: 279280.

Juan García, A. d. (1987): Los enterramientos musulmanes del circo romano de Toledo. Toledo. 
Jusué Simonena, C., y Tabar Sarrías, M. I. (1995): "Estelas funerarias en Navarra. Su evolución en el tiempo". Actas del VI Congreso Internacional de Estelas Funerarias: 77-103, Pamplona.

Larrea, J. J. (2016): “Las iglesias de los vascones: una problemática antigua y un registro arqueológico nuevo (siglos VI-VII)". Nailos, 3: 22 1-248.

López de los Mozos, J. R. (1988): "Una estela discoidea en la iglesia de Santa María la Antigua de Ávila". Cuadernos Abulenses 9: 253-257.

López de los Mozos, J. R. (2004): "La estela y la muerte". Actas del VII Congreso Internacional de Estelas Funerarias: 33-72, Santander.

López Hernández, F. (1992): "Estelas funerarias de La Horcajada". Estudios Abulenses, 9: 139-141.

Martín López, M. E., (2017): "Las estelas funerarias medievales del Museo de Riaño (León)". Homenaje a María Ruiz Trapero: 245-269, Museo Casa de la Moneda.

Martínez, S., Crespo, M., y M. Calvente (2009): "Historiografía y nuevas aportaciones científicas al estudio del yacimiento arqueológico de "La Mezquita" (Cadalso de los Vidrios)". VIfornadas de Patrimonio Arqueológico en la Comunidad de Madrid. Madrid: 499-503.

Menchón Bes, J. J. (2004): "Estelas medievales, contextos aqueológicos y documentales ¿un objetivo imposible?". Actas del VII Congreso Internacional de Estelas Funerarias: 653-686, Santander.

Menchón i Bes, J. J. (1994): “Estelas visigodas en la península ibérica, aproximación a su problemática: cronología y funcionalidad". Actas del V Congreso Internacional de Estelas Funerarias, vol. 2: 377403, Soria.

Nogales Basarrate, T. (1994): "Las estelas funerarias en el mundo clásico en la Península Ibérica: el ejemplo emeritense". Actas del V Congreso Internacional de Estelas Funerarias, vol. 1: 201-210, Soria.

Oliva Cózar, Y., Martínez Enamorado, V. y A. Torremocha Silva (2004): "Estelas funerarias de época merí halladas en Algeciras (Cádiz)". Actas del VII Congreso Internacional de Estelas Funerarias, vol. 3: 807 838, Santander.
Pascual Mayoral, M., y M. Pascual Mayoral (1999): "Estelas discoidea de La Rioja". Antigüedady cristianismo: Monografias históricas sobre la Antigüedad tardía, 16: 313-368.

Pérez Rodríguez-Aragón, F. (1993): “Las estelas funerarias de época tardoantigua en la mitad norte de la península ibérica". Boletín del Seminario de Estudios de Arte y Arqueología, LIX: 183-198.

Pérez, J. A. (1997): Diccionario de Símbolos y Mitos. Madrid.

Pinar, J. y L. Turell (2007): "Ornamenta vel vestimenta ex sepulchro absolutere. Reflexiones en torno a la presencia de tejidos, adornos y accesorios de indumentaria en el mundo funerario del Mediterráneo tardoantiguo". Collectanea Christiana Orientalia 4: 127-167, https://doi.org/10.21071/cco.v4i.84.

Pozuelo Ruano, A. (2009): "Estelas discoideas de la sierra del Guadarrama". Revista de investigación Cuadernos de Estudio, 23: 12-38.

Quintanilla Martínez, E. (1995): "Las estelas funerarias recogidas por la Comisión Provincial de Monumentos Históricos y Artísticos de Navarra". Cuadernos de etnología y etnografia de Navarra, 66: 581586.

Ramos Benito, A. (2012): “Aportación al estudio de las estelas en la provincia de Burgos: estelas medievales en el curso medio del Arlanza". Mundos medievales: espacios, sociedades y poder: homenaje al profesor fosé Ángel García de Cortázar, vol 1: 807-822, Universidad de Cantabria.

Sánchez, A. L. (1995): Informe de la intervención arqueológica en los terrenos de "La Mezquita" (Cadalso de los Vidrios, Madrid). (Inédito). Dirección General de Patrimonio de la Comunidad de Madrid.

Silgo, L. (1989): "Las estelas discoidales valencianas". Estelas discoideas de la península Ibérica: 41 1-424, Madrid.

Tabar Sarrías, M. I. (1993): "La colección de estelas discoideas del Museo de Navarra". Cuadernos de etnología y etnografia de Navarra, 61: 91-189.

Vives, J. de (1963): Concilios Visigóticos e Hispanorromanos. Barcelona-Madrid.

Williams, H. (2010): "Engendered bodies and objects of memory in Final Phase graves". Burial in Later Anglo-Saxon England: 25-37, Oxford. 